\title{
Posing Arithmetic Word Problems in a Sentence Integration Learning Environment in English and Indonesian: A Utilization Analysis
}

\author{
Nur Hasanah*,**, Yusuke Hayashi* and Tsukasa Hirashima*
}

(Received 14 June 2018 and accepted in revised form 15 February 2019)

\begin{abstract}
Learning through problem posing is an essential way to understand problem structures in order to solve problems. The Triplet Structure Model defines the structure of arithmetic word problems solved by one-step addition or subtraction. Monsakun is a software for learning through problem posing in arithmetical word problems based on the Triplet Structure Model. The practical use of Monsakun in the Japanese language shows a learning effect on problem solving, as well as its usefulness for learning through problem posing. This study investigates whether the model works in languages other than Japanese. An analysis of the use of Monsakun by Japanese children and adults shows no significant difference between them. Another analysis of the use of Monsakun in English or Indonesian by non-native Japanese adults also shows no significant difference. We conclude that the Triplet Structure Model is not dependent on the Japanese language and has the potential to contribute to learning arithmetic word problems in languages other than Japanese.
\end{abstract}

Keywords: problem posing, arithmetic word problems, elementary school students, learning analytics

\section{Introduction}

Learning through problem posing is a new pedagogical approach in mathematics education that involves generating new problems in addition to solving pre-formulated problems ${ }^{(1)}$. It is a significant way to promote learners' understanding of arithmetic word problems $^{(2,3)}$. Despite its lack of popularity compared to problem solving, realization of its importance has led to fast-growing research in various aspects of learning activities $^{(4,5)}$. It has been shown that students who were instructed in generating problems improved their problem-solving abilities and attitudes toward math ${ }^{(6)}$.

The practical implementation of learning by problem posing in classrooms is not efficient. Teachers generally teach students to solve problems, but it is also important to assess students' understanding of word problems and diagnose their misconceptions ${ }^{(7)}$. During the process of solving arithmetic word problems, learners go through four processes: translation, integration, planning, and execution ${ }^{(8)}$. Translation and integration are referred to as the problem comprehension process, while the other aspects are part of the problem execution process. In other words, learners need to be able to

\footnotetext{
*Graduate School of Information Engineering, Hiroshima

University, Japan

**School of Business, IPB University, Indonesia
}

comprehend the problem before they execute it. Learning by problem posing is a way to promote understanding of word problems by students. However, students generally pose limited but diverse problems, and teachers need more time to assess and give feedback to students' posed problems ${ }^{(9)}$.

Automation of the assessment process and feedback in the problem posing learning system is an important topic when bringing this practice into the classroom. Although limited in number, some researchers have built systems such as AnimalWatch to address simple arithmetic operations with 5th-grade students in elementary schools $^{(10)}$ and fractions with middle school students $^{(11)}$, as well as a system to analyze a variety of problems posed by undergraduate students based on a given example ${ }^{(12)}$.

An interactive learning environment for problem posing of simple addition and subtraction has been developed and used in several Japanese elementary schools and has shown some positive effects on learning of arithmetic word problems ${ }^{(13-15)}$. The problem posing learning system, known as Monsakun, is based on the Triplet Structure $\operatorname{Model}^{(14,16)}$, which describes an arithmetic word problem structure in the sentence integration process. In Monsakun, a learner is provided with a set of sentence cards and a numerical expression and is required to pose arithmetic word problems by selecting 
and arranging the appropriate cards. Based on the report of practical use, this problem posing method has been found valuable for learners, especially in lower grades ${ }^{(14)}$.

This study investigates whether the Triplet Structure Model can work with languages other than Japanese. The integration process of solving arithmetic word problems involves processing the linguistic meaning into arithmetical formulas which are similar in any language ${ }^{(8)}$. A study about the role of language and visuospatial representation in mathematical thinking shows that exact arithmetic knowledge is stored in a language-specific format, while quantity manipulation is conducted using a language-independent representation of number magnitude in visuospatial processing ${ }^{(17)}$. On this basis, the expected role of the Triplet Structure Model is to describe quantitative information to bridge the gap between linguistic and numerical information. Quantitative information consists of numbers with their meanings derived from linguistic information represented as sentences in a story. Although the meaning of numbers is not represented in the numerical information expressed as equations, it is necessary to ensure consistency between the linguistic and numerical information. In this sense, the Triplet Structure Model must have a relationship with language. If the relationship depends on Japanese, the model has a disadvantage for arithmetic word problems in any language other than Japanese.

In previous studies, Japanese children accepted Monsakun in practical study in the classroom ${ }^{(13,14)}$. The analysis of the use of Monsakun by Japanese elementary school students and university students has shown that the trends of correctness rate among levels in Monsakun are similar between children and adults ${ }^{(18)}$.

In this study, we compare the use of Monsakun in Japanese and in English and Indonesian to check the dependency of the relationship between the model and the linguistic information of a certain language. First, we conduct a more in-depth analysis of the learning data of Japanese native children and adults, steps and mistakes, satisfied constraints, and error occurrence, to clarify Japanese native learners' thinking when posing word problems in Monsakun. Then, we analyze the use of Monsakun by non-Japanese native university students speaking English or Indonesian and compare their learning data with Japanese data. If they can complete the tasks in Monsakun, and the trend of usage data is not different among languages, the Triplet Structure Model could be considered as a basis for thinking about arithmetic word problems, and the model would not be dependent on Japanese. If both non-native and native Japanese adults can pose problems in Monsakun and Japanese children have learned the nature of arithmetic word problems and posed problems in the same manner as Japanese adults, it is hoped that Monsakun can contribute to English and Indonesian children's learning of arithmetic word problems as well.

The research was conducted based on the following research questions:

1. How do Japanese adults pose problems in Monsakun compared to Japanese elementary school children?

a. Is Monsakun acceptable to Japanese adults?

b. Is the acceptance similar or not to that of Japanese children?

2. Is Monsakun in a language other than Japanese acceptable to non-native Japanese speakers?

Due to resource limitations, we were unable to conduct a study of foreign children. In this study, we investigated Monsakun use in an experimental study of university students in English and Indonesian languages as a first step in the study of Monsakun in foreign languages.

The paper is organized as follows. The next section presents the theoretical background of problem posing activities in Monsakun and includes the system introduction, Triplet Structure Model, and types of word problems and constraints on their structure. The third section explains the analysis of Japanese children and adults to clarify whether there are differences between Japanese children and adults in the use of Monsakun. The followed section investigated the use of Monsakun by non-native Japanese, English, and Indonesian adults and compares the results with Japanese adults. Finally, the last section concludes this paper and provides suggestions for future work.

\section{Theoretical Background}

\subsection{Learning Through Problem Posing with Monsakun}

MONSAKUN provides assignments for learners, as shown in Figure 1. A problem posing assignment includes a certain type of story and calculation relation as the requirements and several sentence cards, com- 


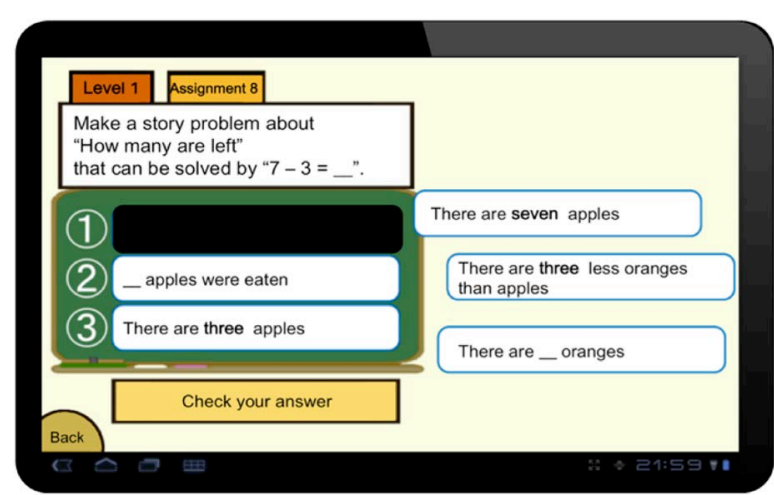

Figure 1. Interface of Monsakun in English Language.

posed of necessary cards and dummy cards. The learner poses a problem by dragging the card into the three blanks and arranging them in an order which satisfies the requirements. In this assignment, the learner needs to pose the following problem: [There are 7 apples. apples were eaten. There are 3 apples].

When the learner has arranged three cards and pushes the check button, the system analyzes the answer. If the learner has answered correctly, he or she proceeds to the next assignment. If the learner's answer is wrong, the system gives feedback, and the learner can correct his mistake.

This software has been put to several years of practical use in elementary schools and has been evaluated in teacher group meetings in Japan. Based on previous research, the usefulness of MONSAKUN was evaluated by pre- and post-tests, as well as by a questionnaire. It was confirmed that the problem posing exercise is effective for improving students' problem posing and problem categorization abilities. Furthermore, long-term use of MONSAKUN in an elementary school showed that students and teachers considered it useful for learning and that they enjoyed using this system continuously ${ }^{(13,}$ 19, 20).

\subsection{Triplet Structure Model}

The Triplet Structure Model describes the meaning of different quantities in arithmetic word problems and how they compose different types of problem. An arithmetic word problem solved by addition or subtraction is composed of two "independent quantity sentences" and one "relative quantity sentence." The combination of different sentences creates a different role for each of the sentences ${ }^{(16)}$.

There are two types of numerical relation in arithmetic word problems: "problem numerical relation" and "calculation numerical relation." In the example [I have 7 oranges. I buy 4 oranges. I have "?" oranges.], to derive the answer, the calculation is $7-4$, and the answer is 3. According to the triplet structure model, the problem numerical relation is " $7-4=$ ?," and the calculation of numerical relation is also the same. This type of problem is known as a "forward-thinking problem."

Meanwhile, in the example [I have "?" oranges. I buy 4 oranges. I have 3 oranges.], to derive the answer, the calculation is $4+3$, and the answer is 7 . According to the Triplet Structure Model, the numerical relation in the problem is "? $-4=3$," while the calculation numerical relation is " $4+3=7$." This type of problem, in which the calculation and problem numerical relation are different, is called a "reverse thinking problem." This type of problem is more difficult for students than forwardthinking problems, because a learner is required not only to understand the story but also to derive the calculation from the story.

\subsection{Types of Word Problems and Con- straints}

There are four types of stories in arithmetic word problems ${ }^{(16)}$. Addition stories are categorized into two types - increase stories and combination stories - while subtraction stories are categorized into two typesdecrease stories and comparison stories. Each story is composed of two independent quantity sentences and one relative quantity sentence. An independent quantity sentence can be used in any problem, while a relative quantity sentence is only used for one specific story problem.

Considering the types of numerical relation (problem and calculation) and types of problem (forward and reverse thinking), Monsakun contains six levels of assignments distinguished by types of problems ${ }^{(21)}$.

Based on the task model of problem posing and the format of assignments in Monsakun, there are five main constraints that must be satisfied in posed problems: (1) calculation, (2) story type, (3) number, (4) concepts/ objects, and (5) sentence structure. When a posed problem satisfies all five constraints, the required problem in the assignment is successfully posed. When a posed 
problem satisfies less than five constraints, the posed problem partially fills the requirements, and the unsatisfied constraints represent the cause of the inadequateness for the requirements. This also means that the posed problem is not meaningless, because it still satisfies some constraints. When a posed problem satisfies no constraint, the problem is meaningless.

\section{Analysis of Monsakun Use by Japanese Children and Adults}

In this section, an analysis of Japanese children and adult subjects was conducted to answer Research Question 1, as follows:

1. How do Japanese adults pose problems in Monsakun compared to Japanese elementary school children?

a. Is Monsakun acceptable to Japanese adults?

b. Is the acceptance similar to that of Japanese children?

We aimed to show that adult subjects were able to accept and use Monsakun and that their performance resembled that of elementary school students.

\subsection{Participants}

In the first part of this study, the problem posing of Japanese university students was analyzed in comparison with that of elementary school students. Although the main targets of Monsakun are elementary school students, we investigated whether our learning environment was also acceptable to adults, in this case, university students. The research question was whether children and adults have similar tendencies of thought when posing word problems using Monsakun. In this part, 39 first grade elementary school students and 53 university students participated in the practical use of Monsakun Japanese. All participants were native Japanese.

\subsection{Materials and Procedures}

Practical use by elementary school students, as described in Yamamoto et al. ${ }^{(21)}$, was conducted in nine class sessions, while Monsakun was used in seven of those class sessions. Use by Japanese children was as an exercise of learning arithmetic word problems in the regular mathematics class. As a usual exercise in classes, children engaged in using Monsakun and tried to get correct answers. Each session started with Monsakun use for five minutes, continued with the usual classroom teaching activity for 35 minutes, and concluded with Monsakun use for 5 minutes. The teacher was involved in every session. During this practical use, elementary school students used Monsakun as exercises in their usual classes. In the classes, they also learned to pose arithmetic word problems together, guided by a teacher. After conducting several classroom sessions with MONSAKUN, they were able to pose problems.

On the other hand, the university students had already learned arithmetic word problems and possessed the knowledge necessary to solve basic word problems. They were only expected to learn how to pose problems with the use of Monsakun. In the experiment with university students, they were first given an explanation of the software, and then they posed problems using Monsakun over a given period. The use of Monsakun was conducted as part of a lecture on interactive learning environments. The tasks assigned to them in the lecture included producing a report about the mechanism and effectiveness of Monsakun based on both the teachers' explanation and the experience of use.

\subsection{Design and Analysis}

The log data from Level 1, Level 3, and Level 5 assignments were analyzed to measure subjects' problem posing. Level 2 and Level 4 were omitted because they only contained three assignments from the same story type each, while other levels contained 12 assignments from four different story types.

First, the average of steps and mistakes in each level was analyzed using ANOVA to show trends in different subject ages/languages. Then, the proportion of satisfied constraints in actual students' answers and possible assignment setting was analyzed using a Chisquare test. If learners posed problems randomly, the proportion would be close to the proportion set in the assignments. Afterward, the difference in proportions among assignments of the same story type was analyzed. If learners posed problems with some consideration, the proportion would reflect their thoughts.

We placed an emphasis on the analysis of satisfied constraints in the posed problems. If learners posed problems randomly without thinking, they would pose many meaningless problems or less meaningful prob- 
Table 1. Average Steps and Mistakes (ANOVA).

\begin{tabular}{l|cccccc}
\hline & $M(S D)$ & Level 1 & Level 3 & Level 5 & $p$ & Sig \\
\hline \multirow{2}{*}{ STEPS } & JP kids & $7.57(3.25)$ & $6.90(2.80)$ & $38.8(16.46)$ & $1.08 \mathrm{E}-30$ & $* *$ \\
& JP adult & $5.51(2.53)$ & $4.24(1.11)$ & $7.93(3.39)$ & $1.61 \mathrm{E}-11$ & $* *$ \\
\hline \multirow{2}{*}{ MISTAKES } & JP kids & $0.47(0.52)$ & $0.61(0.54)$ & $6.09(2.59)$ & $2.56 \mathrm{E}-34$ & $* *$ \\
& JP adult & $0.33(0.38)$ & $0.18(0.18)$ & $0.79(0.63)$ & $5.09 \mathrm{E}-11$ & $* *$ \\
\hline
\end{tabular}

Table 2. Analysis of Average Steps and Mistakes (TukeyKramer).

\begin{tabular}{l|cc|cc}
\hline & \multicolumn{2}{|c|}{ STEPS } & \multicolumn{2}{c}{ MISTAKES } \\
\hline sig & JP kids & JP adult & JP kids & JP adult \\
\hline L1-L3 & no & no & no & yes \\
\hline L1-L5 & yes & yes & yes & yes \\
\hline L3-L5 & yes & yes & yes & yes \\
\hline
\end{tabular}

lems in terms of the constraints, that is, they did not think about the structure of arithmetic word problems. However, if learners posed problems with some sort of consideration, the percentage of meaningful answers would be higher than that of meaningless answers.

\subsection{Results}

\subsubsection{Analysis of Steps and Mistakes}

The average of steps and mistakes shows how many steps students needed in order to pose a correct problem in one assignment, and how many mistakes they made during the problem posing. Ideally, a student would only need three steps to pose a correct problem, because a problem in Monsakun consists of the arrangement of three simple sentence cards. Tables 1 and 2 show average steps and mistakes of Japanese elementary school students and university students.

ANOVA and Tukey-Kramer analysis were used to compare steps and mistakes between Level 1, Level 3, and Level 5. In both groups, we observed significant differences in average steps and mistakes in Level 1 compared to Level 5, as well as in Level 3 compared to Level 5.

\subsubsection{Analysis of Constraints in Level 5}

The meaningfulness of a posed problem has been defined as a way to assess learners' thoughts. A posed problem is meaningful when it satisfies one or more constraints, and it is meaningless when the problem does not satisfy any constraint ${ }^{(22,23)}$. In the analysis, we categorized posed problems and examined the kinds of problems students posed.

To reiterate, there are five constraints to be satisfied to form a correct problem in Monsakun. The posed problems were categorized in terms of the number of satisfied constraints; subsequently, the difference between the occurrence of satisfied constraints in students' posed problems and the possible number of satisfied constraints in the assignment settings were analyzed by a Chi-square test.

We applied a Chi-square test to the counts of each number of satisfied constraints in the settings and the occurrence. If the occurrence follows the proportion of the setting, it indicates that students' problem posing in Monsakun is random. Table 3 shows the proportion of satisfied constraints set in the assignment and the occurrence in Japanese children (kids) and adults, as well as the results of the correlation test.

Table 3 shows the correlation analysis results of the system's setting combination compared to the first attempt occurrence combination of Japanese children and adults (\%) grouped by story type: Combination (1-3), Increase (4-6), Decrease (7-9), and Comparison (10-12).

\subsection{Consideration}

From the analysis of steps and mistakes by Japanese children and adults, in both groups, there was a significant difference in the averages of steps and mistakes in Level 1 compared to Level 5, as well as in Level 3 compared to Level 5. This shows that, in both groups, Level 5 was more challenging than Level 1 and Level 3; in other words, both faced similar difficulties in Level 5.

The correlation analysis of the satisfied constraints shows a significant difference between the occurrence 
Table 3. Distributions of Satisfied Constraints (Chi-Sq. test).

\begin{tabular}{|c|c|c|c|c|c|c|c|c|c|}
\hline \multirow[b]{2}{*}{ Asg } & \multirow[b]{2}{*}{ Country } & \multirow[b]{2}{*}{ Constraint } & \multicolumn{6}{|c|}{ Satisfied Constraints (\%) } & \multirow{2}{*}{$\begin{array}{c}p \text {-Values in } \\
\text { Chi-Sq. test } \\
\text { with the setting }\end{array}$} \\
\hline & & & 0 & 1 & 2 & 3 & 4 & 5 & \\
\hline \multirow[t]{3}{*}{$1-3$} & & Setting & 15.67 & 45.00 & 27.33 & & 6.00 & 6.00 & \\
\hline & JP-Kids & Occurrence & $3.45 * *$ & $21.55 * *$ & $17.24 *$ & & $14.66 * *$ & $43.10 * *$ & $2.70 \mathrm{E}-48 * *$ \\
\hline & JP-Adults & Occurrence & $5.66 * *$ & $6.29 * *$ & $3.77 * *$ & & $13.84 * *$ & $70.44 * *$ & $6.52 \mathrm{E}-151 * *$ \\
\hline \multirow[t]{3}{*}{$4-6$} & & Setting & & 68.33 & 24.44 & 1.11 & 4.44 & 1.67 & \\
\hline & JP-Kids & Occurrence & & $29.57 * *$ & $15.65+$ & $11.3 * *$ & $30.43 * *$ & $13.04 * *$ & $2.70 \mathrm{E}-58 * *$ \\
\hline & JP-Adults & Occurrence & & $22.64 * *$ & $6.29 * *$ & $8.81 * *$ & $19.50 * *$ & $42.77 * *$ & $0.00 \mathrm{E}+00 * *$ \\
\hline \multirow[t]{3}{*}{$7-9$} & & Setting & & 29.67 & 26.00 & 1.00 & 2.33 & 1.00 & \\
\hline & JP-Kids & Occurrence & & $12.93 * *$ & $26.72+$ & $4.31+$ & $19.83 * *$ & $19.83 * *$ & $2.29 \mathrm{E}-54 * *$ \\
\hline & JP-Adults & Occurrence & & $3.77 * *$ & $12.58 * *$ & $0.00 \mathrm{~ns}$ & $15.09 * *$ & $68.55 * *$ & $0.00 \mathrm{E}+00 * *$ \\
\hline \multirow[t]{3}{*}{$10-12$} & & Setting & 14.33 & 38.67 & 35.00 & & 6.00 & 6.00 & \\
\hline & JP-Kids & Occurrence & $5.41 *$ & $10.81 * *$ & $27.03 \mathrm{~ns}$ & & $29.73 * *$ & $27.03 * *$ & $1.60 \mathrm{E}-42 * *$ \\
\hline & JP-Adults & Occurrence & $4.40 * *$ & $15.72 * *$ & $13.21 * *$ & & $5.66 \mathrm{~ns}$ & $61.01 * *$ & $3.94 \mathrm{E}-110 * *$ \\
\hline
\end{tabular}

and settings in all the assignments $(p<.05)$. This shows that neither Japanese children nor adults pose problems in a random way. We found that both groups pose problems by satisfying as many constraints as possible because the ratio of subjects posing problems satisfying constraints less than two was lower than the setting and those posing problems satisfying constraints more than three was higher than the setting.

To answer our RQ1, "How do Japanese adults use Monsakun compared to Japanese elementary school children?," the analysis shows that the groups are not different: both faced similar difficulties in Level 5, and they posed problems, not in a random way but by trying to satisfy as many constraints as possible. This result shows that, as with Japanese children, Monsakun can also be acceptable for Japanese adults as a basis to think about arithmetic word problems.

\section{Investigation of Monsakun Use in Multiple Languages}

In this section, we investigate RQ2, "Is Monsakun use acceptable in languages other than Japanese?", through the experimental use of Monsakun in English and Indonesian languages.

\subsection{Participants}

The second part of this study aims to analyze learners' problem posing in other languages to determine whether the Monsakun structure depends on the Japanese language or not. In this part, non-native Japanese university students took part in an experiment using Monsakun in English or Indonesian. Thirty-seven students used the software in English, and 35 students used it in Indonesian. There was no overlap between the two groups. Participants of Monsakun in English were international students from the US, Europe, Asia, and African regions who were studying at a Japanese university and had adequate English comprehension ability. Participants of Monsakun in Indonesia were Indonesian students studying at a Japanese university.

\subsection{Materials and Procedures}

Participants used the Monsakun Tablet to learn problem posing of one-stop addition and subtraction in their respective languages (English or Indonesian). The software was first developed in Japanese. Conversion to English and Indonesian was carried out through consultation with native speakers of the languages and elementary school mathematics teachers of their respective lan- 
Table 4. Analysis of Average Steps and Mistakes in Multiple Languages (ANOVA).

\begin{tabular}{|c|c|c|c|c|c|c|}
\hline & $M(S D)$ & Level 1 & Level 3 & Level 5 & $p$ & sig \\
\hline \multirow[t]{3}{*}{ STEPS } & JP & $5.51(2.53)$ & $4.24(1.11)$ & $7.93(3.39)$ & $1.61 \mathrm{E}-11$ & $* *$ \\
\hline & EN & $5.15(2.15)$ & $5.54(1.82)$ & $14.09(9.24)$ & $3.42 \mathrm{E}-11$ & $* *$ \\
\hline & IND & $5.32(2.15)$ & $7.45(3.68)$ & $18.83(11.98)$ & 4.12E-12 & $* *$ \\
\hline \multirow[t]{3}{*}{ MISTAKES } & JP & $0.33(0.38)$ & $0.18(0.18)$ & $0.79(0.63)$ & $5.09 \mathrm{E}-11$ & $* *$ \\
\hline & $\mathrm{EN}$ & $0.28(0.40)$ & $0.36(0.31)$ & $1.73(1.78)$ & $1.50 \mathrm{E}-08$ & ** \\
\hline & IND & $0.34(0.35)$ & $0.76(0.60)$ & $2.59(2.34)$ & $1.24 \mathrm{E}-09$ & $* *$ \\
\hline
\end{tabular}

guages, to ensure that the context remained intact and that translated sentences conformed to different mathematical sentence structures in different languages. As shown in Figure 1, Monsakun in English and Indonesian does not include any Japanese and does not require Japanese literacy.

In the experiment, the university students were first provided with an explanation of the software, and then they posed problems over a given period. After the software use, participants of Monsakun English and Indonesia responded to eight 6-point Likert-scale items in a questionnaire about Monsakun use (Table 7). The questionnaire was adapted from the report of practical use in Japanese elementary schools by Yamamoto et al. ${ }^{(21)}$ A free writing section was included at the end of the questionnaire for participants to share their thoughts about the software and provide advice or criticism for improvement.

\subsection{Design and Analysis}

Similar to the first part of this study, the log data from Level 1, Level 3, and Level 5 were investigated. The average of the steps and mistakes was analyzed, followed by a correlation analysis of the satisfied constraints occurring in subjects' posed problems compared to the system settings. The questionnaire was analyzed to discover foreign students' subjective reception of problem posing using Monsakun. As mentioned in the Introduction, previous studies have shown that Monsakun is accepted by Japanese ${ }^{(13,14)}$. Here, we investigate whether Monsakun is accepted by non-Japanese native adults using log data as the objective data and the questionnaire as the subjective data.

\subsection{Results}

\subsubsection{Steps and Mistakes}

For the international subjects group, we observed
Table 5. Analysis of Average Steps and Mistakes in Multiple Languages (Tukey-Kramer).

\begin{tabular}{c|c|c|c|c|c|c}
\hline & \multicolumn{3}{|c|}{ STEPS } & \multicolumn{3}{c}{ MISTAKES } \\
\hline sig & JP & EN & IND & JP & EN & IND \\
\hline L1-L3 & no & no & no & yes & no & no \\
\hline L1-L5 & yes & yes & yes & yes & yes & yes \\
\hline L3-L5 & yes & yes & yes & yes & yes & yes \\
\hline
\end{tabular}

the average steps and mistakes in each level. Tables 4 and 5 show average steps and mistakes of JP, EN, and IND subjects. ANOVA and Tukey-Kramer analysis were used to compare steps and mistakes between Level 1, Level 3, and Level 5 in each language.

\subsubsection{Analysis of Constraints in Level 5}

The analysis of satisfied constraints in Japanese, English, and Indonesian subjects is shown in Table 6. A Chi-square test was conducted between each group of subjects' answers to the system's possible combinations of cards.

Table 6 shows the correlation analysis results of the system setting combination compared to the first attempt occurrence combination of Japanese, English, and Indonesian adults (\%) grouped by story type: Combination (1-3), Increase (4-6), Decrease (7-9), and Comparison (10-12).

\subsubsection{Satisfied Constraints in Frequent Errors}

We have previously explained meaningful and meaningless errors in relation to the constraints they satisfied. In the next analysis, the frequent errors from each group of subjects were identified and analyzed with regard to the type of constraint that subjects were trying to satisfy despite working on wrong problems. The 
POSING ARITHMETIC WORD PROBLEMS IN A SENTENCE INTEGRATION LEARNING ENVIRONMENT IN ENGLISH AND INDONESIAN

Table 6. Distributions of Satisfied Constraints (Chi-Sq. test).

\begin{tabular}{|c|c|c|c|c|c|c|c|c|c|}
\hline \multirow{2}{*}{ Asg } & \multirow{2}{*}{ Country } & \multirow{2}{*}{ Constraint } & \multicolumn{6}{|c|}{ Satisfied constraints $(\%)$} & \multirow{2}{*}{$\begin{array}{c}p \text {-Values in Chi-Sq. test } \\
\text { with the setting }\end{array}$} \\
\hline & & & 0 & 1 & 2 & 3 & 4 & 5 & \\
\hline \multirow{4}{*}{$1-3$} & & Setting & 15.7 & 45.0 & 27.3 & & 6.0 & 6.0 & \\
\hline & JP & Occurrence & $5.7 * *$ & $6.3 * *$ & $3.8 * *$ & & $13.8 * *$ & $70.4 * *$ & $6.5 \mathrm{E}-151 * *$ \\
\hline & IND & Occurrence & $5.6 * *$ & $9.5 * *$ & $7.1 * *$ & & $11.1+$ & $66.7 * *$ & $6.8 \mathrm{E}-96 * *$ \\
\hline & EN & Occurrence & $6.3 * *$ & $13.5 * *$ & $4.8^{* *}$ & & $4.8 \mathrm{~ns}$ & $70.6 * *$ & $1.6 \mathrm{E}-104 * *$ \\
\hline \multirow{4}{*}{$4-6$} & & Setting & & 68.3 & 24.4 & 1.1 & 4.4 & 1.7 & \\
\hline & JP & Occurrence & & $22.6 * *$ & $6.3 * *$ & $8.8 * *$ & $19.5 * *$ & $42.8 * *$ & $0.0 \mathrm{E}+00 * *$ \\
\hline & IND & Occurrence & & $26.2 * *$ & $10.3 * *$ & $10.3 * *$ & $16.7 * *$ & $36.5 * *$ & $1.5 \mathrm{E}-167 * *$ \\
\hline & EN & Occurrence & & $21.4 * *$ & $9.5 * *$ & $13.5 * *$ & $23.0 * *$ & $32.5 * *$ & $3.1 \mathrm{E}-159 * *$ \\
\hline \multirow{4}{*}{$7-9$} & & Setting & & 49.4 & 43.3 & 1.7 & 3.9 & 1.7 & \\
\hline & JP & Occurrence & & $3.8 * *$ & $12.6 * *$ & $0.0 \mathrm{~ns}$ & $15.1 * *$ & $68.6 * *$ & $0.0 \mathrm{E}+00 * *$ \\
\hline & IND & Occurrence & & $7.1 * *$ & $38.1 \mathrm{~ns}$ & $0.0 \mathrm{~ns}$ & $17.5 * *$ & $37.3 * *$ & $7.4 \mathrm{E}-163 * *$ \\
\hline & EN & Occurrence & & $8.7 * *$ & $11.9 * *$ & $2.4 \mathrm{~ns}$ & $9.5 *$ & $67.5 * *$ & $0.0 \mathrm{E}+00 * *$ \\
\hline \multirow{4}{*}{$10-12$} & & Setting & 14.3 & 38.7 & 35.0 & & 6.0 & 6.0 & \\
\hline & $\mathrm{JP}$ & Occurrence & $4.4 * *$ & $15.7 * *$ & $13.2 * *$ & & $5.7 \mathrm{~ns}$ & $61.0 * *$ & $3.9 \mathrm{E}-110 * *$ \\
\hline & IND & Occurrence & $2.4 * *$ & $7.1 * *$ & $21.4 * *$ & & $21.4 * *$ & $47.6 * *$ & $6.1 \mathrm{E}-62 * *$ \\
\hline & EN & Occurrence & $4.0 * *$ & $11.1 * *$ & $9.5 * *$ & & $23.8 * *$ & $51.6 * *$ & $1.5 \mathrm{E}-70 * *$ \\
\hline
\end{tabular}

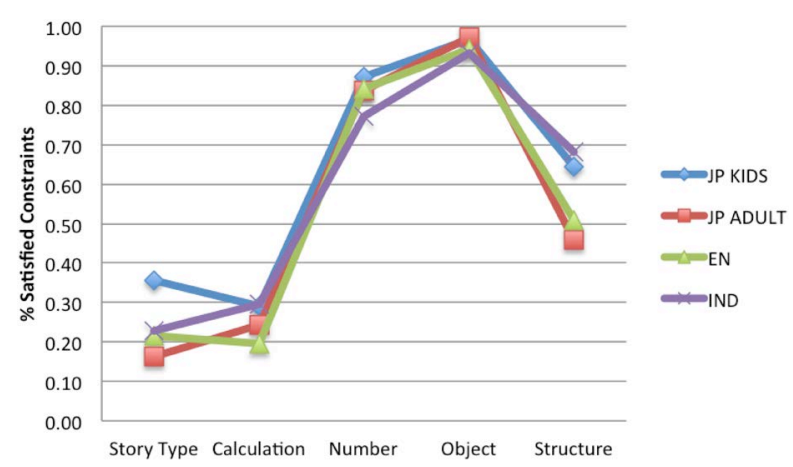

Figure 2. Satisfied Constraints in Frequent Error Combination.

result is shown in Figure 2. It is concluded that regardless of subjects' age and nationality, they followed a similar line of thinking to satisfy certain constraints when they posed a problem in Monsakun. They had some difficulty satisfying number and object constraints, while structure, story type, and calculation con- straints were a struggle for them. The subjects' difficulty in calculation constraint can be observed from this analysis, especially since Level 5 provides reverse thinking problems in which the answer formula is not given directly to the learner (unlike in previous levels). 


\subsubsection{Questionnaire Result}

Table 7 shows the questionnaire items, while Figure 3 shows the result of Monsakun experience use for English subjects $(n=37)$ and Indonesian subjects $(n=35)$. The left part of the graph shows negative responses from the subjects (weakly disagree, disagree, strongly disagree), while the right part shows positive responses (weakly agree, agree, strongly agree).

We observe similar responses from both English and Indonesian subjects. Most subjects agree that posing arithmetic word problems on Monsakun are enjoyable (Q1); however, it is not easy to pose word problems (Q2). They also agree that posing problems is useful for arithmetic (Q3, Q4). While they found Monsakun to be fairly easy to use (Q5), the assignments required some effort to understand (Q6). Nevertheless, feedback was comprehensible (Q7). They also expressed interest in taking part in classes with problem posing activities (Q8).

Table 7. Monsakun Experience Questionnaire.

\begin{tabular}{ll}
\hline & QUESTIONNAIRE \\
\hline Q1 & I enjoy posing arithmetic word problems. \\
Q2 & Arithmetic word problems are easy to pose. \\
Q3 & Posing problems is a good learning method for arithmetic. \\
Q4 & Learning to pose problems makes it easier to solve problems. \\
Q5 & MONSAKUN is easy to use. \\
Q6 & MONSAKUN assignments and sentences are easy to understand. \\
Q7 & MONSAKUN feedback is easy to understand. \\
Q8 & I would like to attend arithmetic classes in which problem posing is used. \\
\hline
\end{tabular}

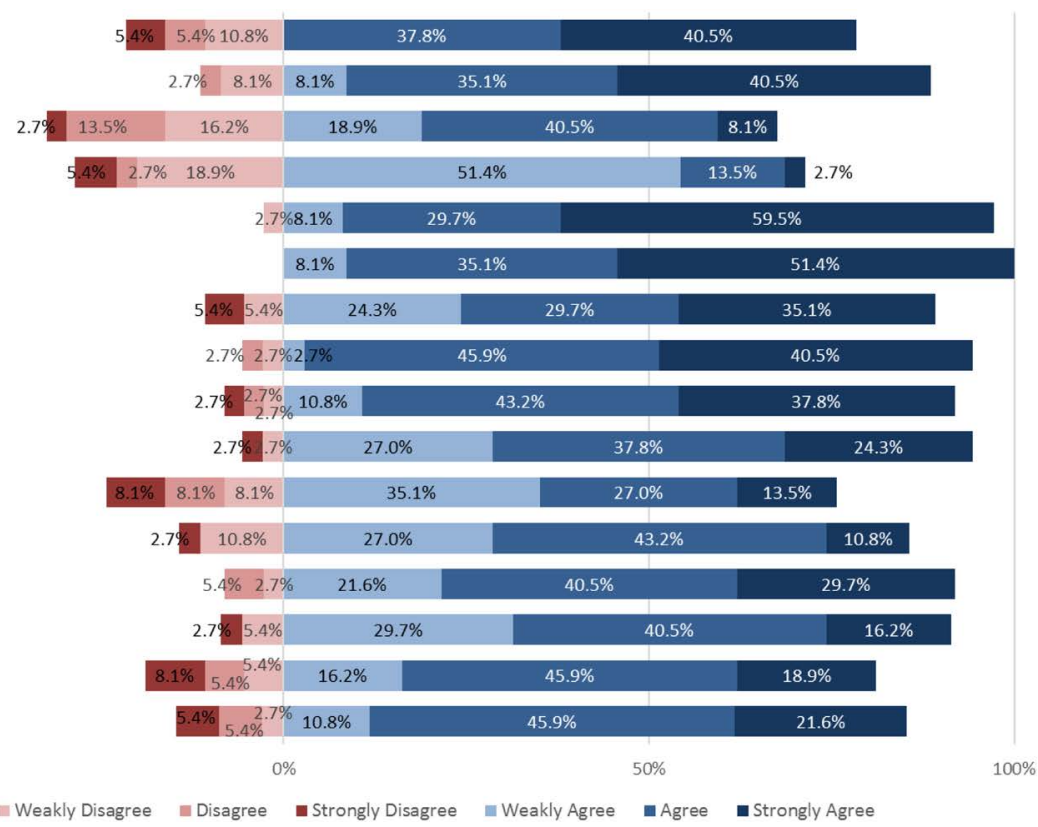

Figure 3. Monsakun Questionnaire Result for English and Indonesian Subjects (\%). 


\subsection{Consideration}

The results of ANOVA and Tukey-Kramer analysis show that, in each language, there are significant differences in the averages of steps and mistakes in Level 1 compared to Level 5, as well as in Level 3 compared to Level 5. This result is similar to that of Japanese children and adults, which means that all groups similarly face difficulties in Level 5.

The result of the Chi-square test showed a significant difference in assignments grouped by story type $(p<0.05)$, which implies that English and Indonesian groups did not pose problems randomly. The ratio of subjects posing problems satisfying constraints less than two was lower than the setting, and those posing problems satisfying constraints more than three was higher than the setting.

To answer RQ2 "Is Monsakun use acceptable in languages other than Japanese?", we showed that all groups faced similar difficulties in Level 5 and that they tried to satisfy as many constraints as possible when posing problems using Monsakun in English or Indonesian, just as Japanese children and adults did.

\section{Conclusion}

This paper investigates whether the Triplet Structure Model depends on the Japanese language or not. We analyzed the use of Monsakun in English or Indonesian by non-native Japanese adults and compared it with its use by Japanese children and adults. The results show that there is no difference among Japanese, English, and Indonesian. This result shows that the Triplet Structure Model has the potential to be acceptable for people to use in languages other than Japanese and to contribute to learning arithmetic word problems.

In the previous study, we investigated Japanese elementary school students' learning outputs of Monsakun problem posing assignments ${ }^{(23,24)}$. The analysis result suggested that learners were observant of the arithmetic word problems' structure and constraints. When posing problems, learners tried to satisfy as many constraints as possible. The result served as evidence of Monsakun effectiveness for learning through problem posing in early school grades.

This study conducted experiments with four groups of subjects: Japanese elementary school students, Japanese university students, non-native Japanese uni- versity students who could speak English, and native Indonesian university students.

Based on the analysis of Japanese university students (adults) and elementary school students (children), tendencies in problem posing were not different among them. The Japanese adults were investigated in similar ways to Japanese elementary school students. Our hypothesis was that, regardless of age and language, learners experience similar thinking when posing arithmetical word problems using Monsakun. The result shows that both groups experienced the same level of difficulty, mostly in Level 5. Furthermore, the tendency when posing problems - that is, to satisfy as many constraints as possible - was found in both Japanese children and adults.

Compared to Japanese, there is no significant difference in problem posing with Monsakun in English or Indonesian. We analyzed the learning outputs of nonnative Japanese students using Monsakun in English or Indonesian. In the experiment, all subjects were able to complete all assignments in Monsakun. The analysis result showed the same characteristics in Japanese, English, and Indonesian subjects' performance and that they underwent similar thinking. The analysis of adults speaking Japanese, English, and Indonesian was essential, since our assumption relates to how the children's groups from the respective languages would conduct their learning using Monsakun.

We infer that by posing problems with Monsakun, regardless of age and language, subjects showed some understanding of the structure of arithmetic word problems. They acquired it based not on posing problems randomly, since the proportion of constraint satisfaction in the occurrence of subjects' answers was significantly different from that of the setting in assignments. Subjects also tried to satisfy as many constraints as possible, as shown by their frequent answers. Based on the results of data analysis and the questionnaire, we suggest that the Triplet Structure Model is acceptable for multiple languages.

With respect to future studies, the implementation and analysis of Monsakun practical use for elementary school students in various countries outside Japan is the most direct suggestion. A more in-depth analysis of students' thinking while posing problems, especially in reverse-thinking problems, is another suggestion for further study. 


\section{Acknowledgement}

This work was supported by JSPS KAKENHI Grant Number $15 \mathrm{H} 02931$

\section{References}

(1) Silver, E. A. and Cai, J.: "An Analysis of Arithmetic Problem Posing by Middle School Students", J. of Research in Mathematics Education, Vol. 27, No. 5, pp. 521-539 (1996).

(2) Brown, S. I. and Walter, M. I.: The Art of Problem Posing. Erlbaum, Hillsdale, NJ (1990).

(3) Polya, G.: How to Solve It: A New Aspect of Mathematical Method. Princeton University Press, New Jersey (1957).

(4) English, L. D.: "Problem Posing in Elementary Curriculum", in Teaching Mathematics through Problem Solving, eds. Lester, F. and Charles, R., Virginia: National Council of Teachers of Mathematics (2003).

(5) National Council of Teachers of Mathematics. Principles and Standards for School Mathematics. Reston: NCTM (2000).

(6) Winograd, K.: "Writing, Solving and Sharing Original Math Story Problems: Case Studies in the Cognitive Behaviors of Fifth Grade Children", in Annual Meeting of the American Educational Research Association, (Chicago, IL, April, 1991) (1991).

(7) Carpenter, T. P., Fennema, E., Peterson, P. L. et al.: "Teachers' Pedagogical Content Knowledge of Students' Problem Solving in Elementary Arithmetic", J. for Research in Mathematics Education, Vol. 19, Vol. 5, pp. 385-401 (1988).

(8) Mayer, R. E.: The Promise of Educational Psychology Vol 1: Learning in the Content Areas. Merrill Prentice Hall, Upper Sadle River, NJ (1999).

(9) Nakano, A., Hirashima, T. and Takeuchi, A.: ProblemMaking Practice to Master Solution-Methods in Intelligent Learning Environment, Proc. of ICCE'99, pp. 891-898 (1999).

(10) Arroyo, I. and Woolf, B. P.: "Students in AWE: Changing Their Role from Consumers to Producers of ITS Content", 11th International Conference on Artificial Intelligence in Education, Workshop on Advanced Technologies for Math Education (2003).

(11) Beal, C. R., Arroyo, I., Cohen, P. R. et al.: "Evaluation of AnimalWatch: An Intelligent Tutoring System for Arithmetic and Fractions", J. of Interactive Online Learning, Vol. 9, No. 1, pp. 64-77 (2010).

(12) Kojima, K. and Miwa, K.: "A System That Facilitates
Diverse Thinking in Problem Posing", Int'l J. of Arti-Ficial Intelligence in Education, Vol. 18, pp. 209-236 (2008).

(13) Hirashima, T., Yokoyama, T., Okamoto, M. et al.: "Learning by Problem-Posing as Sentence-Integration and Experimental Use", Proc. of AIED2007, pp. 254-261 (2007).

(14) Kurayama, M. and Hirashima, T.: "Interactive Learning Environment Designed Based on Task Model of ProblemPosing", Proc.of ICCE2010 (2010).

(15) Nakano, A., Hirashima, T. and Takeuchi, A: An Evaluation of Intelligent Learning Environment for Problem Posing, Proc. of ITS2002, pp. 861-872 (2002).

(16) Hirashima, T., Yamamoto, M., Hayashi, Y.: Triplet Structure Model of Arithmetical Word Problems for Learning by Problem-Posing, Proc. of HCII2014, pp. 42-50 (2014).

(17) Dehaene, S., Spelke, E., Pinel, P. et al.: "Sources of Mathematical Thinking: Behavioral and Brain-Imaging Evidence", Science 284 (5416), pp. 970-974 (1999).

(18) Hasanah, N., Hayashi, Y. and Hirashima, T.: "Utilization Analysis of Monsakun in Multiple Languages as Validation of Triplet Structure Model of Arithmetical Word Problems", The $72^{\text {nd }}$ SIG on Advanced Learning Science and Technology, Vol. B4, No. 02, pp. 5-9 (2014).

(19) Hirashima, T., Yokoyama, T., Okamoto, M., et al.: "Longterm Use of Learning Environment for Problem-Posing in Arithmetical Word Problems", Proc. of ICCE, pp. 817824 (2008)

(20) Hirashima, T. and Kurayama, M.: "Learning by ProblemPosing for Reverse-Thinking Problems", Proc. of AIED2011, pp. 123-130 (2011).

(21) Yamamoto, S., Kanbe, T., Yoshida, Y. et al.: "A Case Study of Learning by Problem-Posing in Introductory Phase of Arithmetic Word Problems", Proc. of the $20^{\text {th }}$ International Conference on Computers in Education, pp. 25-32 (2012).

(22) Hasanah, N., Hayashi, Y. and Hirashima, T.: "Analysis of Problem-Posing Process of Arithmetical Word Problem as Sentence Integration: Viewpoint of First Selected Sentence". Emerging Issues in Smart Learning, pp. 85-88. Berlin Heidelberg Springer (2015).

(23) Hasanah, N., Hayashi, Y. and Hirashima, T.: "An Analysis of Learner Outputs in Problem Posing as SentenceIntegration in Arithmetic Word Problems", Research and Practice in Technology Enhanced Learning, Vol. 12 (2017). doi:10.1186/s41039-017-0049-5

(24) Supianto, A. A., Hayashi, Y. and Hirashima, T.: "Visualizations of Problem-Posing Activity Sequences Toward Modeling the Thinking Process", Research and Practice in Technology Enhanced Learning, Vol. 11 (2016). doi:10.1186/s41039016-0042-4 


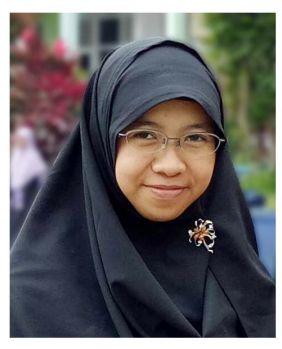

Nur Hasanah received her B.CS. degree from the Department of Computer Science, Bogor Agricultural University (IPB), Indonesia, in 2009 and her M.E. from the University of Tsukuba in 2012. She is a Ph.D. candidate at the Learning Engineering Laboratory at Hiroshima University. Her research interests are artificial intelligence, data mining, and learning engineering. She received the Best Student Paper Award at the IFSA \& AFSS conference in 2011 and the Best Student Paper Award at the ICCE conference in 2015.

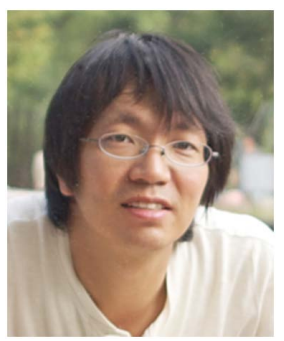

Yusuke Hayashi has been an associate professor in the Department of Information Engineering, Graduate School of Engineering, Hiroshima University since 2012. He received his Ph.D. degree from the Graduate School of Engineering Science, Osaka University, Japan, in 2003. He was a research associate in the School of Knowledge Science, Japan Advanced Institute of Science and Technology (JAIST) from 2003 to 2005; assistant professor in the Department of Knowledge Systems, Institute of Scientific and Industrial Research (ISIR), Osaka University from 2005 to 2010; and associate professor in the Information Technology Center, Nagoya University from 2010 to 2012. He has been engaged in research on knowledge modeling, ontological engineering, and learning engineering. He received the Best Paper Award at the ICCE conference in 2006.

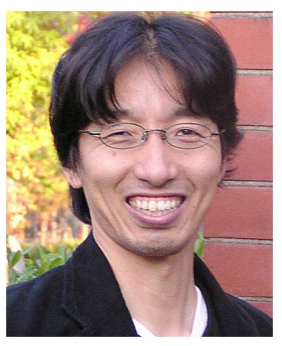

Tsukasa Hirashima received his B.E., M.E., and Ph.D. from Osaka University in 1986, 1988, and 1991, respectively. $\mathrm{He}$ worked at the Institute of Scientific and Industrial Research, Osaka University, as a research associate and lecturer from 1991 to 1997. From 1997 to 2003, he worked in the Graduate School of Information Engineering at the Kyushu Institute of Technology as an associate professor. He has been a professor in the Graduate School, Department of Information Engineering, Hiroshima University since 2004. Learning engineering is his major research field. $\mathrm{He}$ has received international awards, including the Outstanding Paper Award of ED-MEDIA95, the Best Paper Award of ICCE 2001 and 2002, an Honorable Mention Award at AIED2009, and an APSCE Distinguished Researcher Award in 2009. 